\title{
Bioactivation of Yttria-Stabilized Tetragonal Zirconia Surface via a Chemical Treatment Processing Using a Calcium-Phosphate Slurry
}

\author{
Mitsuhiro Hirano*1, Yusuke Konaka*2 and Naofumi Ohtsu*3 \\ School of Earth, Energy and Environmental Engineering, Faculty of Engineering, Kitami Institute of Technology, Kitami 090-8507, Japan
}

The present study demonstrates that the bioactivation of bioinert yttria-stabilized tetragonal zirconia (YSZ) substrates is achieved through a chemical treatment process using a calcium phosphate slurry. The slurry processing is simple: a YSZ substrate was buried in a slurry agent prepared by mixing calcium phosphate powder and distilled water, and thereafter, the slurry including the substrate was heated in air. Treating by the processing, tiny hydroxyapatite (HAp) particles were deposited on the YSZ surface. The amount of the particles increased with an increase in the heating temperature up to $1223 \mathrm{~K}$, while setting the temperature beyond $1373 \mathrm{~K}$ induced thermal decomposition into tricalcium phosphate (TCP) and calcium oxide (CaO). When immersing in Hanks' balanced saline solution to evaluate bioactivation, HAp precipitation was only observed on the slurry-treated surface, and the mass thickness of the precipitation was enhanced with increasing heating temperatures up to $1223 \mathrm{~K}$. Slurry-treated YSZ at $1223 \mathrm{~K}$ did not adversely affect the adhesion and proliferation of osteoblast-like cells. On the other hand, calcification of the cells was significantly promoted, indicating the activation of bone formation. In conclusion, slurry processing is a valuable technique that enhances the bioactivity of YSZ substrates with a simple one-step process. [doi:10.2320/matertrans.MT-M2021081]

(Received May 10, 2021; Accepted June 11, 2021; Published August 2, 2021)

Keywords: zirconia, dental implant, hydroxyapatite, chemical treatment, calcification

\section{Introduction}

Yttria-stabilized tetragonal zirconia (YSZ) has been used for a dental implant material in recent years because of its aesthetic value, low cytotoxicity, low risk of allergic reaction, and excellent flexural strength. ${ }^{1-4)}$ Current dental implant materials such as titanium (Ti) and its alloy discolor the gingiva surrounding the implant with its dark metallic color, while YSZ with its white color, like teeth, overcomes this problem. ${ }^{5,6)}$ In addition, the risk of allergic reactions induced by the release of metallic ions cannot be completely eliminated when a metallic material is employed; conversely, this risk is reduced in the case of a YSZ implant because of its high chemical stability. ${ }^{7,8)}$ Therefore, metal-free implants composed of YSZ would provide further benefit in dental treatments, making it attractive for patients and doctors.

However, YSZ is a bioinert material, and thus the progress of osteogenesis on the surface is comparatively slow. In particular, the bioinert YSZ implant surface has exhibited insufficient osseointegration as compared to $\mathrm{Ti}^{9}{ }^{9,10)}$ As a result, a comparatively longer duration is required to achieve strong integration between YSZ implants and the surrounding hard tissue, which inevitably causes surgical failures and poor quality of life for patients. To promote YSZ as a generic dental implant material, this fatal drawback must be addressed.

Surface modification is a demonstrated strategy to enhance osteogenesis on the surface of an implant. ${ }^{5,11)}$ In particular, coating the implant surface with hydroxyapatite (HAp; $\left.\mathrm{Ca}_{10}\left(\mathrm{PO}_{4}\right)_{6}(\mathrm{OH})_{2}\right)$ is well-established technique, which is the main component of teeth and bone. ${ }^{12,13)}$ As a coating

\footnotetext{
${ }^{* 1}$ Graduate Student, Kitami Institute of Technology. Present address Functional Metallic Materials Laboratory, Research Division of Metallic Materials, Osaka Research Institute of Industrial Science and Technology, Izumi 594-1157, Japan

${ }^{* 2}$ Graduate Student, Kitami Institute of Technology. Present address: Zeria Pharmaceutical Co., Ltd., Tokyo 103-8351, Japan

${ }^{* 3}$ Corresponding author, E-mail: nohtsu@mail.kitami-it.ac.jp
}

technique, plasma spraying is the most popular technique in the case of a Ti implant. ${ }^{14)}$ However, the high temperature environment of the plasma spraying process at approximately $10,000 \mathrm{~K}$ induces a phase transition of YSZ, resulting in the deterioration of its mechanical properties. ${ }^{14-17)}$ As an alternative to the plasma spraying process, some researchers have developed biomimetic techniques using simulated body fluids to coat YSZ substrates. ${ }^{18-20)}$ This technique is a simple processing to form a calcium phosphate layer via soaking in a solution at a low temperature ranging from 298 to $338 \mathrm{~K}$, thereby preventing the deterioration of mechanical properties. However, the adhesion strength of the layer is considerably low, which may induce serious clinical problems such as inflammation due to the debris of coating after surgeries.

For a decade, our research group has gained attentions for a chemical treatment process using a calcium-phosphate slurry. ${ }^{21,22)}$ The slurry processing is simple as follows: slurry agent is prepared by mixing calcium-phosphate powders and distilled water, after which a substrate is buried in the slurry and heated in air. Heretofore, we demonstrated that this processing enables to form HAp-including surfaces on metallic materials; for instance, treating a $\mathrm{Ti}$ substrate led to the formation of HAp layer with thickness in approximately $50-100 \mathrm{~nm}$, and in the case of zirconium (Zr) substrates, tiny HAp particles with sizes on the nano-meter scale were deposited on the surface. The calcification of osteoblast-like cells was enhanced on these surfaces treated by slurry processing as compared with an untreated surface. ${ }^{22,23)}$ Moreover, when implanted in rat tibia, bone regeneration on the substrate was activated. ${ }^{24)}$ The effectiveness of slurry processing on a metallic surface has already been demonstrated; nevertheless, applying the process to a ceramic material such as YSZ has not been conducted. The heating temperature required for slurry processing is approximately $1000 \mathrm{~K}$, which is below the phase transition temperature of YSZ.

In the present study, therefore, we attempted to apply slurry processing to YSZ substrates with the aim of obtaining 
an HAp-including surface that functions to facilitate osteogenesis. For this purpose, YSZ substrates were treated by slurry processing at various heating temperatures, and thereafter the surfaces characteristics as well as the response to osteoblast-like cells were investigated. Based on these results, we discussed the applicability of slurry processing to YSZ substrates as a bioactivation process.

\section{Experimental Procedure}

\subsection{Specimen preparation}

A YSZ substrate containing $3 \mathrm{~mol} \%$ yttria $(15 \mathrm{~mm}$ in diameter and $1 \mathrm{~mm}$ in thickness, AS ONE Co., Japan) was used as the substrate. The surface was mechanically polished using \#1200 grade diamond abrasive paper. The calcium phosphate powders (tribasic calcium phosphate; $3 \mathrm{Ca}_{3}\left(\mathrm{PO}_{4}\right)_{2}$. $\mathrm{Ca}(\mathrm{OH})_{2}$; Sigma Aldrich Inc.), with average particle size of $50 \mathrm{~nm}$, of $1 \mathrm{~g}$ and distilled water with $1.5 \mathrm{ml}$ were added in a ceramic crucible, after which the slurry agent was prepared via mixing. The YSZ substrates were buried completely in the slurry, and the crucible containing the substrates was heated in air for $2 \mathrm{~h}$. The heating temperature was set in the range from $923 \mathrm{~K}$ to $1373 \mathrm{~K}$, and the temperature was higher than that employed for the processing of metallic substrates such as Ti and Zr. This is because the diffusion of a slurrylike agent to the substrate is an important factor in the formation of HAp-including surfaces, and the diffusion coefficients of the slurry agents in YSZ are lower than that in metallic substrates. ${ }^{25-27)}$ After heating, the substrates were retrieved from the slurry, which were washed ultrasonically using distilled water for $10 \mathrm{~min}$.

\subsection{Surface characterization}

The morphologies of treated YSZ surfaces was characterized using field emission-scanning electron microscope (FESEM; JSM-6701F, JEOL, Japan), which was operated at an acceleration voltage of $5 \mathrm{kV}$ in secondary electron imaging mode. The chemical states of the treated surfaces were evaluated by X-ray photoelectron spectroscopy (XPS; PHI 5000 VersaProbe, ULVAC-PHI, Japan) equipped with monochromatic $\mathrm{Al} \mathrm{K} \alpha$ radiation $(\mathrm{h} \nu=1486.8 \mathrm{eV})$ as $\mathrm{X}$-ray source. The photoelectron take-off angle was set to $45^{\circ}$. C $1 \mathrm{~s}$ peak corresponding to naturally adsorbed hydrocarbon to $284.8 \mathrm{eV}$ was used to correct the binding energies. The backgrounds of the spectra were subtracted using Shirley's method. The mass thickness of the HAp on the specimens was quantified by wavelength dispersive X-ray fluorescence analysis (WDXRF; S8 Tiger, Bruker AXS, Germany) using the fundamental parameter algorithm for the thin film preinstalled in the instrument. The algorithm was set for measuring YSZ surface according to our previous study. ${ }^{22,28)}$

\subsection{Evaluation of bioactivation in simulated body fluid}

The performance of calcium phosphate precipitation on material surfaces in a simulated body fluid is an important property that is correlated with bioactivation as well as osteogenesis. $^{29)}$ Therefore, the specimens were immersed in the solution maintained at $310 \mathrm{~K}$ for $3 \mathrm{~d}$, after which the performance was evaluated by quantifying its amounts precipitated on the surface. Here, Hanks' balanced salt solution (HBSS) was used as a simulated body fluid, which was prepared by dissolving the following substances in distilled water: $\mathrm{NaCl}, \mathrm{KCl}, \mathrm{CaCl}_{2}, \mathrm{MgSO}_{4} \cdot 7 \mathrm{H}_{2} \mathrm{O}, \mathrm{Na}_{2} \mathrm{HPO}_{4}$, $\mathrm{KH}_{2} \mathrm{PO}_{4}$, and $\mathrm{NaHCO}_{3}$. After immersing, the specimens were rinsed with distilled water and dried at $313 \mathrm{~K}$ in air. Quantification of the precipitated calcium phosphate was performed using WDXRF.

\subsection{In vitro cell culture test}

Human osteoblast-like Saos-2 cell line was purchased from RIKEN BioResource Center. The cells were cultured in McCoy's 5A modified medium (GIBCO BRL, USA) supplemented with $15 \%$ fetal bovine serum (JR Scientific, USA) and $1 \%$ antibiotic-antimycotic $\left(100 \mathrm{U} \mathrm{mL}^{-1}\right.$ penicillin, $100 \mu \mathrm{g} \mathrm{mL}^{-1}$ streptomycin, and $0.25 \mu \mathrm{g} \mathrm{mL}^{-1}$ amphotericin $\mathrm{B}$; GIBCO BRL, USA) at $37^{\circ} \mathrm{C}$ in a fully humidified atmosphere containing $5 \% \mathrm{CO}_{2}$. The specimens sterilized with $70 \%$ ethanol for $30 \mathrm{~min}$ were placed in 24-well polystyrene cell-culture plates, on which the cells were seeded at $1 \times 10^{5}$ cells $\cdot \mathrm{mL}^{-1}$. Living cells attached to YSZ surfaces were counted after incubating for 6 and $72 \mathrm{~h}$ using a hematocytometer. The cells counted at $6 \mathrm{~h}$ were related to the cell attachment performance, and that at $72 \mathrm{~h}$ showed the cell proliferation performance.

Reaching almost confluence on the substrates, the medium was replaced to induce differentiation of the Saos-2 cells. Here, the McCoy's 5A modified medium supplemented with $2 \mathrm{mmol} \mathrm{L}^{-1} \beta$-glycerophosphate (Merck KGaA, Germany) and $50 \mu \mathrm{g} \mathrm{mL}^{-1}$ L-ascorbic acid (Wako Pure Chemical, Japan) was employed as the differentiation medium. The cells were cultivated for $6 \mathrm{~d}$ with changing for every $3 \mathrm{~d}$. After the cultivation, the calcification of the differentiationinduced cells on the YSZ surface was evaluated by Calcium E-Test Kit Wako (Wako Pure Chemical, Japan). The medium was removed from the 24-well plate, in which $1 \mathrm{M}$ hydrochloric acid was added to dissolve extracellular matrix mineralization formed on the cells. The plate was kept at $4^{\circ} \mathrm{C}$ for $24 \mathrm{~h}$, and subsequently the amount of mineralization was calculated by the standard protocol of the assay kit. Statistical analysis was performed using Student's $t$-test for the data obtained from the tests.

\section{Results}

\subsection{Surface characteristics of slurry-treated YSZ sub- strates}

Figure 1 shows the SEM images of the slurry-treated and untreated YSZ surfaces. Particles with sizes of diameter at approximately $50-100 \mathrm{~nm}$ (indicated by the arrow) were observed on the surfaces treated at temperatures at $923 \mathrm{~K}$, and these sizes of the individual particles and amount increased with raising to temperatures at $1073 \mathrm{~K}$. At the temperature of $1223 \mathrm{~K}$, fine crystal grains were appeared on YSZ substrates. The size of individual particle was enlarged further, which tended to aggregate. Ultimately, the grain and particles were reached to approximately $200-300 \mathrm{~nm}$ on the surface at $1373 \mathrm{~K}$. Elemental analysis using energy dispersive X-ray spectroscopy (EDS) was conducted to identify the elements (Fig. 2). Here, the surface treated at $1373 \mathrm{~K}$ was employed for the analysis. The signals corresponding to $\mathrm{Ca}$ and $\mathrm{P}$ were 

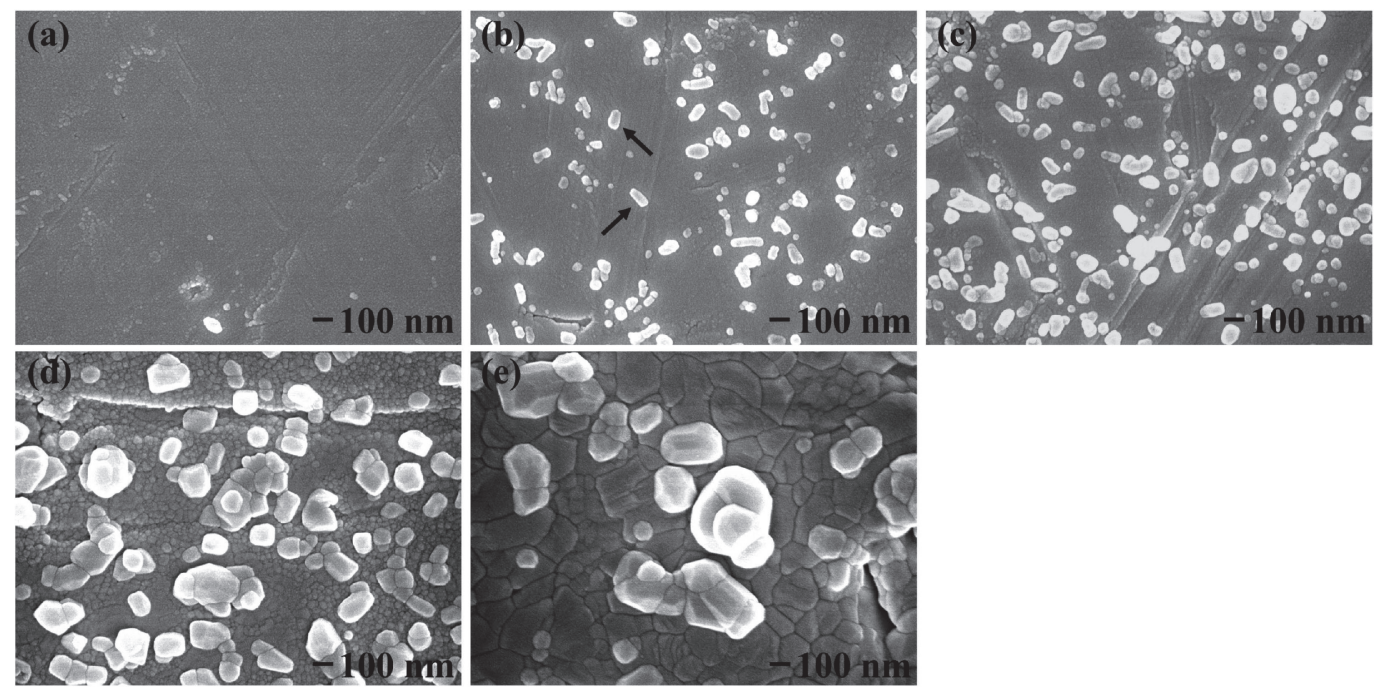

Fig. 1 Surface morphologies of YSZ specimens. (a) Untreated, (b) treated at $923 \mathrm{~K}$, (c) treated at $1073 \mathrm{~K}$, (d) treated at $1223 \mathrm{~K}$, and (e) treated at $1373 \mathrm{~K}$.
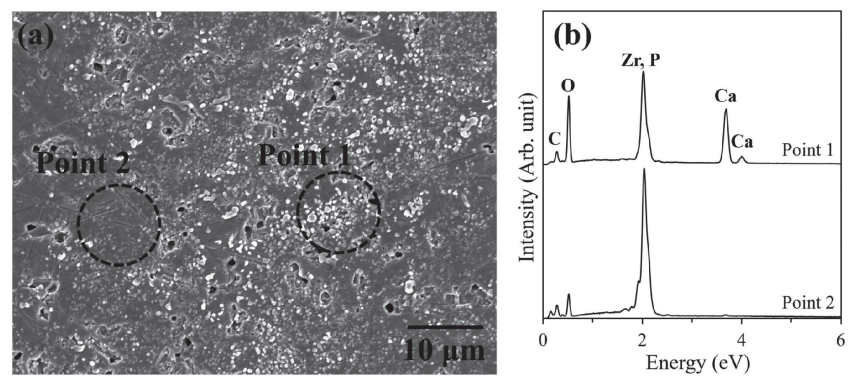

Fig. 2 EDS analyses of specimens treated at $1373 \mathrm{~K}$. (a) SEM image of the surface area selected for elemental analysis, and (b) EDS spectra of the treated surface at Point 1 and 2 .

detected in the area with many particles (indicated by Point 1), but they were hardly detectable in the area without the particles (indicated by Point 2).
XPS narrow spectra corresponding to Ca 2p, P 2p, Zr 3d, and $\mathrm{O} 1 \mathrm{~s}$ were collected from the treated YSZ surfaces. Here, the narrow spectra from the surfaces treated at $1223 \mathrm{~K}$ and $1373 \mathrm{~K}$ are typical features of their spectra. The spectra from the other treated surfaces almost coincided with that for the surface treated at $1223 \mathrm{~K}$. The Ca 2 p spectra overlapped with the $\mathrm{Zr} 3 \mathrm{p}_{1 / 2}$ spectra, and thus, spectral deconvolution was conducted to analyze the $\mathrm{Ca} 2 \mathrm{p}$ spectra accurately (Fig. 3(a)). Herein, the deconvolution was conducted by subtracting the $\mathrm{Zr} 3 \mathrm{p}_{1 / 2}$ part from the overlapping spectra. The $\mathrm{Zr} 3 \mathrm{p}_{1 / 2}$ spectra used for the subtraction was estimated as follows: the spectral shape of $\mathrm{Zr} 3 \mathrm{p}_{1 / 2}$ was obtained by measuring a standard YSZ surface, and its intensity was adjusted based on the theoretical ratio between $\mathrm{Zr} 3 \mathrm{p}_{3 / 2}$ and $3 \mathrm{p}_{1 / 2}$. As shown in Fig. 3(b), the binding energy of the $\mathrm{Ca} 2 \mathrm{p}_{3 / 2}$ spectrum at $1223 \mathrm{~K}$ was $347.1 \mathrm{eV}$, corresponding to a calcium phosphate compound, whereas that at $1373 \mathrm{~K}$ was composed of two
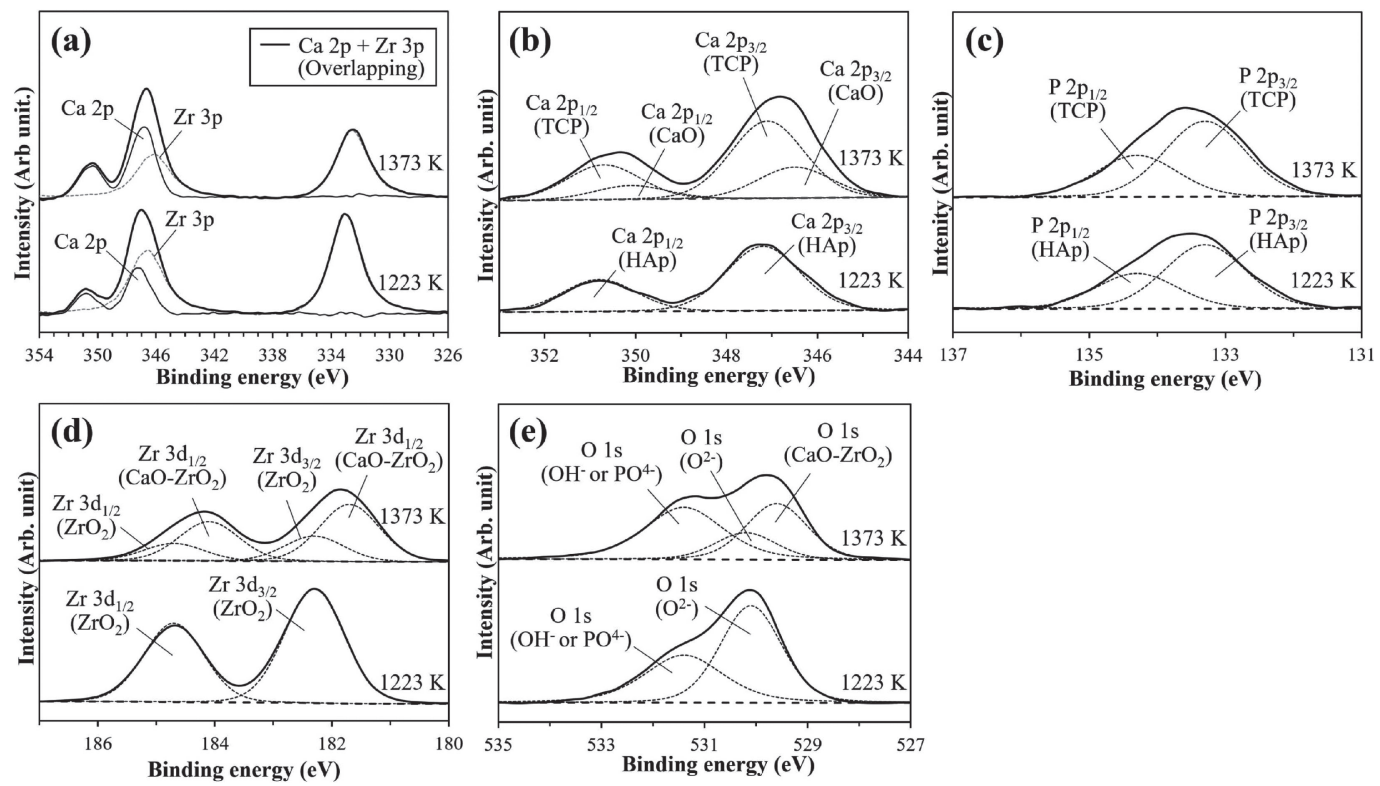

Fig. 3 XPS spectra of the YSZ surface treated at 1223 and $1373 \mathrm{~K}$. (a) Spectral deconvolution of the Ca $2 \mathrm{p}+\mathrm{Zr} 3 \mathrm{p}$ overlapping spectrum, and the narrow spectra of (b) Ca 2p, (c) P 2p, (d) Zr 3d, and (e) O 1s. 
chemical states corresponding to calcium phosphate $(347.1 \mathrm{eV})$ and calcium oxide $(\mathrm{CaO} ; 346.5 \mathrm{eV}) .{ }^{30,31)}$ The binding energy of the $\mathrm{P} 2 \mathrm{p}_{3 / 2}$ was $133.2 \mathrm{eV}$ irrespective of the heating temperature, in agreement with that of the calcium phosphate state. ${ }^{30)}$ Additionally, the atomic ratio of $\mathrm{Ca}$ to $\mathrm{P}([\mathrm{Ca}] /[\mathrm{P}])$ originating from calcium phosphate, which were calculated from the corresponding spectra of $\mathrm{Ca} 2 \mathrm{p}_{3 / 2}$ and $\mathrm{P} 2 \mathrm{p}$, was approximately 1.7 for the $1223 \mathrm{~K}$ surface and 1.5 for the $1373 \mathrm{~K}$ surface, respectively. The former value was consistent with the stoichiometric ratio of HAp, and the latter was that of tricalcium phosphate (TCP). The binding energy of the $\mathrm{Zr} 3 \mathrm{~d}_{5 / 2}$ for the $1223 \mathrm{~K}$ surface was $182.3 \mathrm{eV}$, attributed to $\mathrm{ZrO}_{2}{ }^{32)}$ On the other hand, the spectrum for the $1373 \mathrm{~K}$ surface shifted in the negative direction, which was deconvoluted into two chemical states. The $\mathrm{O} 1 \mathrm{~s}$ spectra for the surface treated at $1223 \mathrm{~K}$ were composed of two peaks: the lower energy peak at $530.1 \mathrm{eV}$ corresponded to the $\mathrm{O}^{2-}$ state and the higher energy peak at $531.4 \mathrm{eV}$ was assigned to $\mathrm{OH}^{-}$and/or $\mathrm{PO}^{4-}$, and that at $1373 \mathrm{~K}$ was similarly shifted as the $\mathrm{Zr} 3 \mathrm{~d}$ spectra. ${ }^{32,33)}$ Here, when YSZ colocalizes with $\mathrm{CaO}$ as a stabilizing agent, it is transformed to fully stabilized cubic- $\mathrm{ZrO}_{2}$ at approximately $1373 \mathrm{~K}$ due to the diffusion of $\mathrm{CaO}^{34}$ ) Furthermore, Majumdar et al. revealed that the binding energies of the $\mathrm{Zr} 3 \mathrm{~d}$ and $\mathrm{O} 1 \mathrm{~s}$ XPS spectra obtained from the $\mathrm{ZrO}_{2}$ substrate were shifted in negative direction as a stabilizing agents was added. ${ }^{35)}$ These studies indicated that the spectral shifts of the $\mathrm{Zr} \mathrm{3d}$ and $\mathrm{O} 1 \mathrm{~s}$ spectra at $1373 \mathrm{~K}$ originated from $\mathrm{CaO}$ diffusing to the YSZ substrates, and thus the lower energy peak was attributed to $\mathrm{CaO}$-diffused $\mathrm{ZrO}_{2}$. Based on the SEM and XPS analytical results, the particles deposited on the treated surface below $1223 \mathrm{~K}$ were HAp, but that on the $1373 \mathrm{~K}$ surface was a complex of TCP and $\mathrm{CaO}$.

The mass thickness of the deposited particles was evaluated quantitatively using WDXRF (Fig. 4). The mass thickness was almost constant for surfaces treated up to $1073 \mathrm{~K}$, while it increased with temperatures beyond $1223 \mathrm{~K}$. It is obvious that the higher heating temperatures facilitated the deposition of calcium phosphate on the substrates.

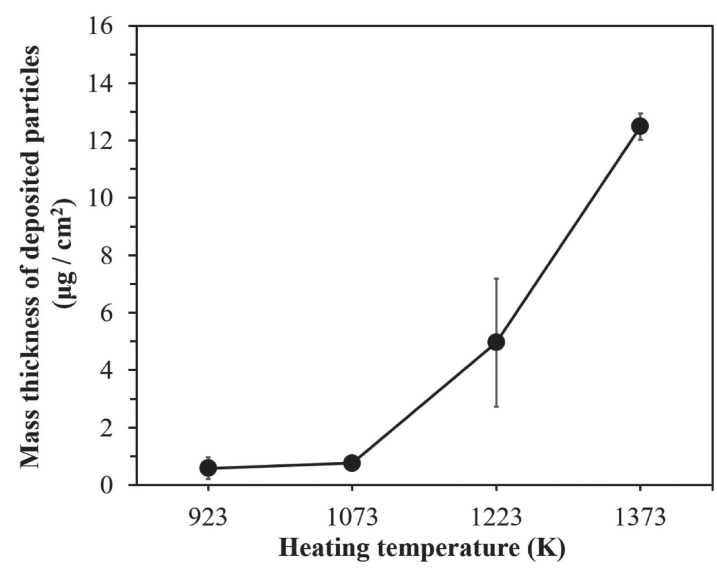

Fig. 4 Variation in mass thickness on YSZ substrates treated with various heating temperatures

\subsection{Performance of calcium phosphate precipitation in HBSS}

The slurry-treated and untreated YSZ substrates were immersed in HBSS for 3 days to investigate the performance of calcium phosphate precipitation. Figure 5 shows the SEM images of the YSZ surfaces after immersion for 3 days. Tiny precipitations were observed on the $923 \mathrm{~K}$ surface (Fig. 5(b)), although the entire surface was not covered. The $1073 \mathrm{~K}$ and $1223 \mathrm{~K}$ surfaces were covered entirely with precipitation, and the precipitation layer appeared thicker on the $1223 \mathrm{~K}$ surface as compared with the $1073 \mathrm{~K}$ surface (Fig. 5(c) and (d)). Nevertheless, this thick precipitation was not found on the $1373 \mathrm{~K}$ surface (Fig. 5(e)), and an original YSZ substrate beneath the precipitation layer was observed partially (indicated by the arrow). WDXRF analysis revealed that the precipitations were composed of $\mathrm{Ca}$ and $\mathrm{P}$, in which the $[\mathrm{Ca}] /[\mathrm{P}]$ ratio was approximately 1.7 , corresponding to that of HAp. The mass thickness of the HAp precipitation, evaluated by WDXRF, was plotted against the heating temperature, as shown in Fig. 6. The mass thickness increased with an increase in heating temperature up to $1223 \mathrm{~K}$, but dropped at $1373 \mathrm{~K}$. Based on these results, it
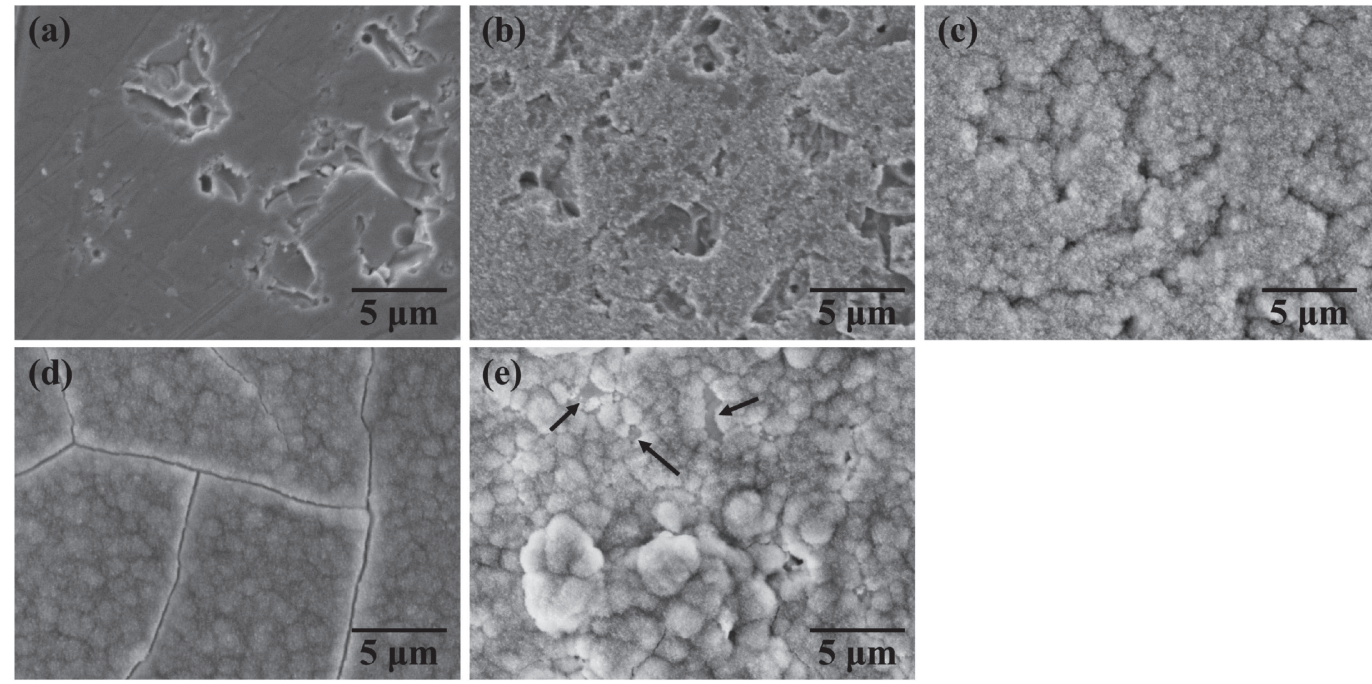

Fig. 5 Surface morphologies after immersing YSZ specimens in HBSS for 3 days. (a) Untreated, (b) treated at $923 \mathrm{~K}$, (c) treated at $1073 \mathrm{~K}$, (d) treated at $1223 \mathrm{~K}$, and (e) treated at $1373 \mathrm{~K}$. 


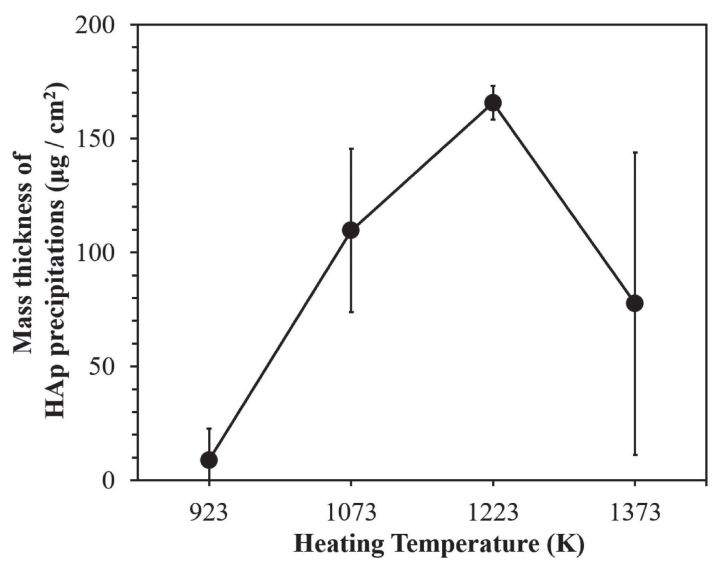

Fig. 6 Mass thickness of HAp precipitations after immersing each YSZ specimens in HBSS for 3 days.

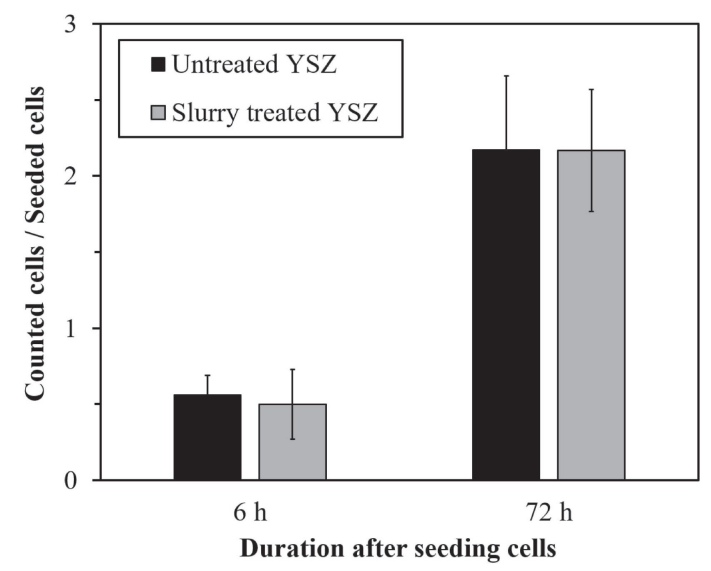

Fig. 7 Cell count values of living Saos-2 cells on untreated and slurrytreated surface after cultivating for 6 and $72 \mathrm{~h}$. There was no statistical difference between the surfaces $(p<0.05)$.

was conjectured that the performance of HAp precipitation varied depending on the heating temperature, and the $1223 \mathrm{~K}$ surface showed the highest performance. It is generally accepted that a biomaterial surface forming HAp precipitation facilitates osteogenesis; thus, an in vitro test was performed only on the $1223 \mathrm{~K}$ surface.

\subsection{Cellular response on treated YSZ substrates}

Figure 7 shows the numbers of living cells on the slurrytreated YSZ surface at $1223 \mathrm{~K}$ and an untreated surface after cultivating for 6 and $72 \mathrm{~h}$. Here, the data were normalized by the number of seeded cells. After cultivating for $6 \mathrm{~h}$, no significant differences in the cell numbers were found between the treated and an untreated surface. The cell numbers were increased at $72 \mathrm{~h}$ on both surfaces, and no significant differences were found.

After differentiation induction, the amount of calcium deposition as a result of extracellular matrix mineralization was quantified at $6 \mathrm{~d}$ (Fig. 8). The amount of calcium deposition on the slurry-treated surface was distinctly higher than that on an untreated surface, and statistical analysis revealed a significant difference. The result suggests that the calcification of osteoblast-like Saos-2 cells, on a YSZ substrate was considerably facilitated by slurry processing.

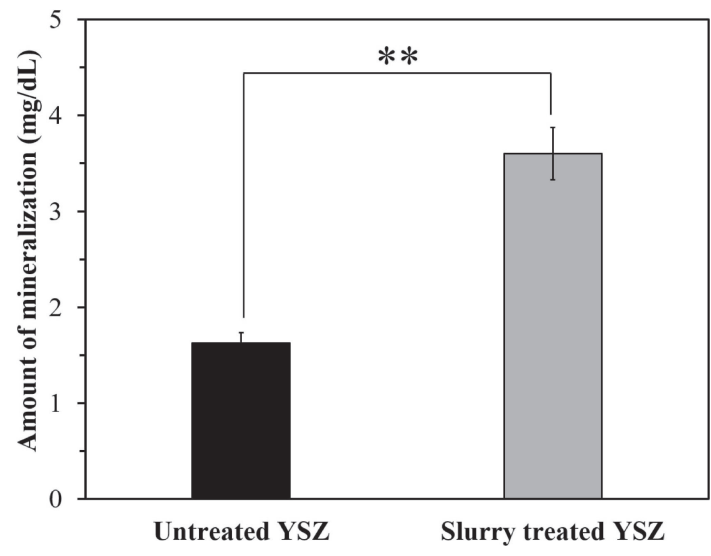

Fig. 8 Amount of mineralization on each surface at $6 \mathrm{~d}$ after inducing differentiation. Statistical difference was determined between the surface by Student's t-test $(* * p<0.01)$.

\section{Discussion}

The experimental results indicated that a HAp-deposited YSZ surface was generated by slurry processing if the heating temperature was increased beyond $923 \mathrm{~K}$. The required heating temperature was approximately $300-700 \mathrm{~K}$ higher than that used for metallic substrates such as $\mathrm{Ti}$ and $\mathrm{Zr}^{21,22)}$ Heating process facilitates the diffusion of $\mathrm{Ca}$ and $\mathrm{P}$, which are constituent elements of the slurry, thereby anchoring the HAp deposits onto a substrate surface. However, the diffusion coefficients of $\mathrm{Ca}$ and $\mathrm{P}$ in $\mathrm{YSZ}$ are much lower than that in a metallic substrate; ${ }^{26,36,37)}$ thus, using a higher heating temperature was the key factor for the formation of the HAp deposited surface on YSZ. Meanwhile, applying a higher heating temperature to a metallic substrate results in the deterioration of the surface mechanical property due to the growth of a low-density oxide layer. ${ }^{38)}$ Therefore, using a high heating temperature in slurry processing is suitable only for ceramic.

In addition, an increase in the heating temperature led to an enlargement in the crystal grain of the YSZ substrate up to approximately $300 \mathrm{~nm}$ (Fig. 1). Such changes may affect the mechanical properties of the YSZ substrate. Ruiz et al. evaluated the effect of heat treatment on the mechanical properties of YSZ and determined that changes in hardness and elastic modulus were hardly found up to $2023 \mathrm{~K}$, although the crystal grain was enlarged to approximately $5 \mu \mathrm{m} .{ }^{17)}$ These properties deteriorated dramatically at $2123 \mathrm{~K}$ due to the occurrence of a phase transformation from the tetragonal phase to the monoclinic phase caused by the diffusion of yttrium to the grain boundary. ${ }^{17,39)}$ Thus, according to these studies, the influence of slurry processing on the mechanical properties of YSZ substrates is negligible. Note that the process temperature of plasma spraying used as an industrial technology for HAp coating is above $10,000 \mathrm{~K}$, which is much higher than the temperature range discussed here.

The amount of calcium phosphate particles deposited on the YSZ substrate increased with an increase in the heating temperature. An increase in the particles enhanced the performance of HAp precipitation during soaking in HBSS up to $1223 \mathrm{~K}$; thus, using higher temperatures seemed to be 
advantageous for bioactivation. However, when the heating temperature was increased above $1373 \mathrm{~K}$, the particles were transformed from HAp to TCP and $\mathrm{CaO}$ (Fig. 3) according to the following reaction: ${ }^{34)}$

$$
\mathrm{Ca}_{10}\left(\mathrm{PO}_{4}\right)_{6}(\mathrm{OH})_{2} \rightarrow \mathrm{Ca}_{3}\left(\mathrm{PO}_{4}\right)_{2}+\mathrm{CaO}+\mathrm{H}_{2} \mathrm{O}
$$

thereby leading to a decrease in the performance. ${ }^{40,41)}$ Therefore, a heating temperature of $1223 \mathrm{~K}$ was found to be the optimal temperature for activating YSZ using slurry processing.

When the cell reactions between the untreated and slurrytreated YSZ surfaces at $1223 \mathrm{~K}$ were compared, there were no significant differences in the number of living cells after cultivating for 6 and $72 \mathrm{~h}$ (Fig. 7). This result was similar to the cell response on the HAp-coated YSZ prepared by aerosol deposition as well as the composite ceramics comprising YSZ and HAp. ${ }^{42,43)}$ Numerous reports have shown that HAp itself and YSZ hardly influenced cell adhesion and proliferation; hence, the present results are reasonable. After the induction of osteoblast-like cell differentiation, the amount of calcium deposition as a result of extracellular matrix mineralization increased significantly when treating by the slurry processing (Fig. 8). Extracellular matrix mineralization is considered to be a maturational marker indicating the degree of cell differentiation. Heretofore, we reported that the HAp-including surface fabricated by slurry processing enhanced calcification as well as alkaline phosphatase activity and osteopontin deposition, which are early and late differentiation markers, respectively. ${ }^{24)}$ Furthermore, when implanted in rat tibia, bone regeneration was promoted earlier. Based on these studies, the HAp-deposited YSZ produced by slurry processing enables similar acceleration of regeneration.

Lastly, we emphasize the additional advantages of slurry processing as compared to conventional techniques such as plasma spraying. Slurry processing can fabricate bioactive surfaces on YSZ using an optimal heating temperature of $1223 \mathrm{~K}$, which does not induce phase transformations and the deterioration of mechanical properties. Furthermore, the processing cost is low because special instruments are unnecessary. Thus, we conclude that slurry processing is applicable as an industrial process for the bioactivation of YSZ surfaces.

\section{Conclusion}

The application of calcium-phosphate slurry processing to YSZ substrates led to the deposition of HAp particles. The amount of deposited particles increased with an increase in the heating temperature during the process, while raising the temperature beyond $1373 \mathrm{~K}$ induced the thermal decomposition of HAp into TCP and $\mathrm{CaO}$. The performance of HAp precipitation in HBSS, as an index of bioactivation, was enhanced by slurry processing up to $1223 \mathrm{~K}$, while such performance was decreased by decomposition of HAp. Cell adhesion and proliferation behaviors on the slurry-treated YSZ surface at $1223 \mathrm{~K}$ were almost similar to those on an untreated surface, indicating that slurry processing does not induce toxicity. On the other hand, the calcification of osteoblast-like cells was significantly facilitated by slurry processing. Chemical treatment using calcium-phosphate slurry is concluded to be a promising industrial process to enhance osteogenesis on YSZ implants.

\section{Acknowledgments}

This work was supported by the Grants-in-aid for Scientific Research (C) (No. 15K06452) from the Ministry of Education, Culture, Sports, Science and Technology (MEXT), Japan. The authors gratefully acknowledge Mr. Misao Yamane from the Kitami Institute of Technology for the assistance with the XPS analysis.

\section{REFERENCES}

1) J. Chevalier: Biomaterials 27 (2006) 535-543.

2) C. Piconi and G. Maccauro: Biomaterials 20 (1999) 1-25.

3) H. Harianawala, M. Kheur, S. Kheur, T. Sethi, A. Bal, M. Burhanpurwala and F. Sayed: J. Adv. Med. Dent. Sci. Res. 4 (2016) 35-39.

4) T. Hanawa: Dent. Mater. J. 39 (2020) 24-36.

5) G. Soon, B. Pingguan-Murphy, K.W. Lai and S.A. Akbar: Ceram. Int 42 (2016) 12543-12555.

6) G.I. Benic, D. Scherrer, M. Sancho-Puchades, D.S. Thoma and C.H.F. Hämmerle: Clin. Implant Dent. Relat. Res. 28 (2017) 192-200.

7) M. Kitagawa, S. Murakami, Y. Akashi, H. Oka, T. Shintani, I. Ogawa, T. Inoue and H. Kurihara: J. Prosthodont. Res. 63 (2019) 309-312.

8) B. Gökçen-Röhlig, A. Saruhanoglu, E.D. Çifter and G. Evlioglu: Int. J. Prosthodont. 23 (2010) 562-565.

9) V. Chappuis, Y. Cavusoglu, R. Gruber, U. Kuchler, D. Buser and D.D. Bosshardt: Clin. Implant Dent. Relat. Res. 18 (2016) 686-698.

10) R. Depprich, H. Zipprich, M. Ommerborn, C. Naujoks, H.P. Wiesmann, S. Kiattavorncharoen, H.C. Lauer, U. Meyer, N.R. Kübler and J. Handsche: Head Face Med. 4 (2008) 30.

11) Y. Liu, B. Rath, M. Tingart and J. Eschweiler: J. Biomed. Mater. Res. A 108 (2020) 470-484.

12) M.J. Olszta, X. Cheng, S.S. Jee, R. Kumar, Y.-Y. Kim, M.J. Kaufman, E.P. Douglas and L.B. Gower: Mater. Sci. Eng. Rep. 58 (2007) 77-116.

13) R.A. Surmenev, M.A. Surmeneva and A.A. Ivanova: Acta Biomater. 10 (2014) 557-579.

14) R.A. Surmenev: Surf. Coat. Tech. 206 (2012) 2035-2056.

15) B. Stawarczyk, M. Özcan, L. Hallmann, A. Ender, A. Mehl and C.H.F. Hämmerlet: Clin. Oral Investig. 17 (2013) 269-274.

16) J. Moon, H. Choi, H. Kim and C. Lee: Surf. Coat. Tech. 155 (2002) $1-10$.

17) L. Ruiz and M.J. Readey: J. Am. Ceram. Soc. 79 (1996) 2331-2340.

18) N.M. Zain, R. Hussain and M.R.A. Kadir: Appl. Surf. Sci. 322 (2014) 169-176.

19) M. Dehestani, D. Zemlyanov, E. Adolfsson and L.A. Stanciu: Appl. Surf. Sci. 425 (2017) 564-575.

20) M. Stefanic and T. Kosmač: J. Eur. Ceram. Soc. 38 (2018) 5264-5269.

21) N. Ohtsu, Y. Nakamura and S. Semboshi: Surf. Coat. Tech. 206 (2012) 2616-2621.

22) M. Hirano, Y. Yokoiwa, S. Komai and N. Ohtsu: Appl. Surf. Sci. 478 (2019) 567-573.

23) N. Ohtsu, M. Hirano and H. Arai: J. Biomed. Mater. Res. A 102 (2014) 3838-3845.

24) T. Ito, N. Ohtsu, M. Tomozawa, M. Hirano, H. Takita, T. Iizuka and A. Yokoyama: J. Biomed. Mater. Res. B Appl. Biomater. 106 (2018) 2716-2724.

$25)$ C. Argirusis, M.A. Taylor, M. Kilo, G. Borchardt, F. Jomard, B. Lesage and O. Kaïtasov: Phys. Chem. Chem. Phys. 6 (2004) 3650-3653.

26) K. Kowalski, A. Bernasik and A. Sadowski: J. Eur. Ceram. Soc. 20 (2000) 2095-2100

27) G.M. Hood: J. Nucl. Mater. 159 (1988) 149-175

28) K. Satoh, M. Komata, M. Mizuhira, K. Wagatsuma and N. Ohtsu: Mater. Trans. 54 (2013) 817-824.

29) T. Kokubo and H. Takadama: Biomaterials 27 (2006) 2907-2915.

30) C.C. Chusuei, D.W. Goodman, M.J.V. Stipdonk, D.R. Justes and E.A. 
Schweikert: Anal. Chem. 71 (1999) 149-153

31) B. Demri and D. Muster: J. Mater. Process. Technol. 55 (1995) $311-$ 314.

32) M. Oishi, Y. Tsutsumi, P. Chen, M. Ashida, H. Doi and T. Hanawa: Surf. Interface Anal. 50 (2018) 587-591.

33) J.E. Arce, A.E. Arce, Y. Aguilar, L. Yate, S. Moya, C. Rincón and O. Gutiérrez: Ceram. Int. 42 (2016) 10322-10331.

34) E. Adolfsson, P.A. Henning and L. Hermansso: J. Am. Ceram. Soc. 83 (2000) 2798-2802.

35) D. Majumdar and D. Chatterjee: J. Appl. Phys. 70 (1991) 988-992.

36) B. Demri, M. Hage-Ali, M. Moritz, J.L. Kahn and D. Muster: Appl Surf. Sci. 108 (1997) 245-249.

37) H. Nakajima, J. Nakazawa, Y. Minonishi and M. Koiwa: Philos. Mag.
A 53 (1986) 427-437.

38) N. Ohtsu, T. Takahara, M. Hirano and H. Arai: Surf. Coat. Tech. 239 (2014) 185-190

39) H.G. Scott: J. Mater. Sci. 10 (1975) 1527-1535.

40) R. Xin, Y. Leng, J. Chen and Q. Zhang: Biomaterials 26 (2005) 64776486.

41) S.C.G. Leeuwenburgh, J.G.C. Wolke, M.C. Siebers, J. Schoonman and J.A. Jansen: Biomaterials 27 (2006) 3368-3378.

42) Y. Cho, J. Hong, H. Ryoo, D. Kim, J. Park and J. Han: J. Dent. Res. 94 (2015) 491-499.

43) G. Peñarrieta-Juanito, M. Cruz, M. Costa, G. Miranda, J. Marques, R. Magini, A. Mata, J.C.M. Souza, J. Caramês and F.S. Silva: Materialia 1 (2018) 3-14 